\title{
Spontaneous Uterine Perforation Due to Pyometra Presenting as Acute Abdomen
}

\author{
Sarada Prasanna Sahoo • Arun Kumar Dora • \\ M. Harika • K. Ramesh Kumar
}

Received: 11 February 2009/Accepted: 25 March 2009 /Published online: 14 April 2011

(C) Association of Surgeons of India 2011

\begin{abstract}
Spontaneous perforation of uterus is rare, its incidence being about $0.01 \%-0.5 \%$. We report a rare case of diffuse peritonitis and pneumoperitoneum caused by spontaneously perforated pyometra. A 50-year postmenopausal lady with abdominal pain was admitted to our hospital. Laparotomy was performed because of the suspicion of gastrointestinal perforation with generalized peritonitis. At laparotomy about $1,500 \mathrm{ml}$ of pus present in peritoneal cavity and whole of alimentary tract and gallbladder were normal.A total abdominal hysterectomy with bilateral salpingooopherectomy was performed. Histopathological study revealed chronic suppurative endometritis with myometritis of the uterus with no evidence of malignancy. Although spontaneously perforated pyometra is rare, a perforated pyometra should therefore be considered when elderly female presents with acute abdomen.
\end{abstract}

Keywords Pyometra $\cdot$ Uterine perforation .

Pneumoperitoneum $\cdot$ Acute abdomen

\section{Introduction}

Pyometra is the accumulation of purulent material in the uterine cavity. The most common cause of pyometra is malignant disease of genital tract and consequence of its treatment (radiotherapy).Other causes are benign tumours like leiomyoma, endometrial polyp, senile cervicitis, puerperal infection and congenital cervical anomalies. Spontaneous rupture of uterus is an extremely rare complication of pyometra.

About 25 cases have been reported in English literature. This paper reports an additional case of spontaneous uterine rupture.

S. P. Sahoo $(\bowtie) \cdot$ A. K. Dora $\cdot$ M. Harika $\cdot$ K. R. Kumar

Alluri Sitarama Raju Academy of Medical Sciences,

Eluru, India

e-mail: drsaradaprasanna@gmail.com

\section{Case Report}

A 50 year postmenopausal lady presented with high grade fever for 1 week and pain abdomen for 1 day.There was no history of any vaginal bleeding nor any procedure done prior to hospitalization. On systemic examination, she was dehydrated, tachypneic and was in shock. Abdominal examination revealed diffuse tenderness with guarding and rigidity. Liver dullness was obliterated and there was presence of free fluid and absence of bowel sounds. On x-ray abdomen there was free gas under domes of diaphragm and on ultrasonography of abdomen there was free fluid.

A provisional diagnosis of hollow viscus perforation was made and exploratory laparotomy done. On laparotomy there was about $1,500 \mathrm{ml}$ of pus present in peritoneal cavity and stomach, duodenum, small and large intestine and liver, gall bladder were normal. On thorough searching, there was a perforation of $0.5 \mathrm{~cm}$ in diameter present in fundus of uterus. With the consent of patient's attendants abdominal hysterectomy with bilateral salpingo-oopherectomy done. On cut section of the resected uterus there was shaggy necrotic black material present with dilated endometrial cavity. Postoperative recovery of the patient was satisfactory except for wound dehiscence for which secondary sutures placed. Histopathological study of surgical specimen revealed chronic suppurative endometritis and myometritis associated with perforation.

\section{Discussion}

Pyometra is common in postmenopausal women and more than $50 \%$ all patients of nonruptured pyometra are asymptomatic [1]. The incidence of pyometra becomes much higher with age and decline in activity; incontinence is also a risk factor [2].

The reported incidence of spontaneous perforation of pyometra is $0.01-0.5 \%$ in gynaecological patients, however as far as elderly patients are concerned, its incidence is $13.6 \%$ [3]. 
The causes of pneumoperitoneum without any GI Tract perforation are perforated pyometra, perforated liver abscess, and ruptured necrotic lesion of liver metastasis. [4]

In conclusion the diagnosis of spontaneous perforation of pyometra is rarely made preoperatively and the possibility of a perforated pyometra should therefore be considered when elderly women suffer from acute abdominal pain. Their management often difficult and hysterectomy and bilateral salpingo-oopherectomy may be the best choice procedure in these patients [5].

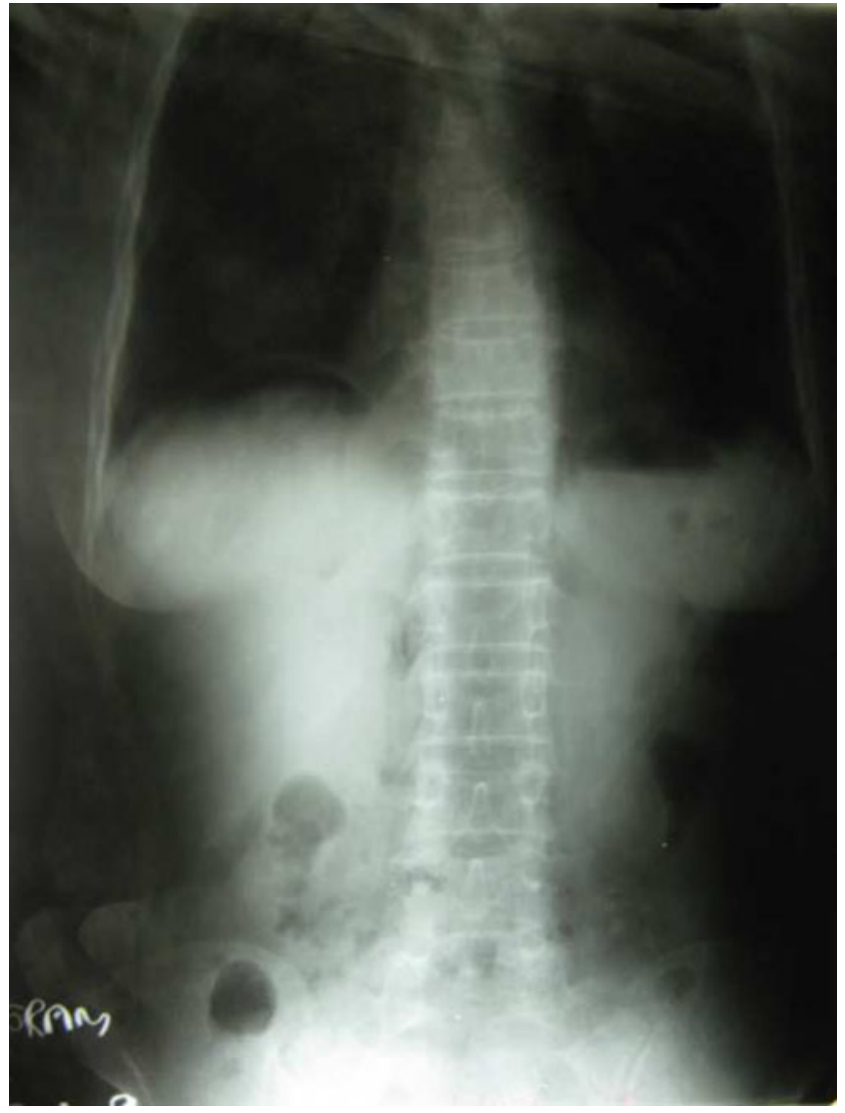

$\mathrm{X}$-ray abdomen showing free gas

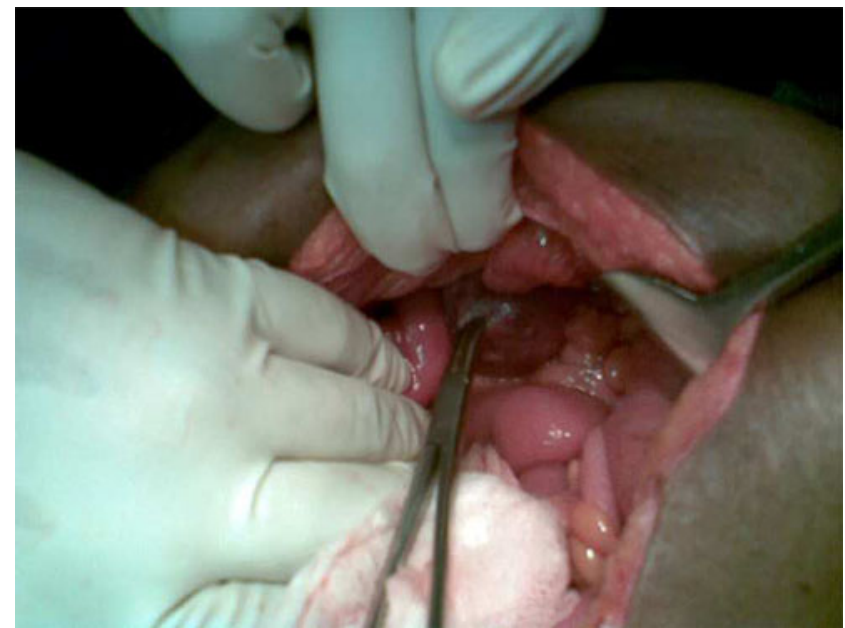

Picture showing uterine perforation

\section{Reference}

1. Hansen PT, Lindholt J (1985) Spontaneously perforated pyometra. A differential diagnosis in acute abdomen. Ann Chir Gynaecol 74 (6):294-295

2. Iwase F, Shimizu H, Koike H et al (2001) Spontaneously perforated pyometra presenting as diffuse peritonitis in older females at nursing homes. J Am Geriatr Soc 49(1):9596

3. Sawabe M, Takubo K, Esaki Y et al (1995) Spontaneous uterine perforation as a serious complication of pyometra in elderly females. Aust NZ J Obstet Gynaecol 35(1):8791

4. Omori H, Asahi H, Inoue $\mathrm{Y}$ et al (2003) Pneumoperitoneum without perforation of the gastrointestinal tract. Dig Surg 20:334338

5. Nakao A, Mimura H, Fujisawa K et al (2000) Generalized peritonitis due to spontaneously perforated pyometra presenting as pneumoperitoneum: report of a case. Surg Today 30(5):454457 